\title{
5 Research Square

\section{Does LDL-C or its phenotype actually predict the risk of cardiovascular diseases in the immediate future? An observational study}

\section{Sufyan Ibrahim}

Kasturba Medical College Manipal https://orcid.org/0000-0001-9127-2738

\section{Anurupa Udupi}

Kasturba Medical College Manipal

\section{Cleeta Rebeiro}

Kasturba Medical College Manipal

\section{Varashree B S}

Kasturba Medical College Manipal

\section{Asha Kamath}

Kasturba Medical College Manipal

Revathi P Shenoy ( $\square$ revathi.shenoy@manipal.edu )

Kasturba Medical College, Manipal, Manipal Academy of Higher Education

\section{Research}

Keywords: LDL-C, sdLDL-C, Cardiovascular diseases, Cholesterol, Disease Markers

Posted Date: January 8th, 2021

DOI: https://doi.org/10.21203/rs.3.rs-141136/v1

License: () (1) This work is licensed under a Creative Commons Attribution 4.0 International License. Read Full License 


\section{Abstract}

\section{Background:}

Cardiovascular diseases (CVDs) are the leading cause of death and disability across the world.

Dyslipidemia, and more specifically, elevated LDL-C has been historically attributed to be one of the key modifiable risk factors associated with atherogenesis. The aim of this study was to determine LDL-C and sdLDL-C, for establishment of their predictive value in the development of CVDs, in order for them to be used as clinical tools to guide the management of CVDs.

\section{Material and Methods:}

One hundred sixty-two (162) serum samples sent for the analysis of lipid profile parameters were studied, which were classified into tests and controls based on the values of calculated LDL-C obtained by Friedewald formula. These samples were then anonymized, and direct LDL-C was estimated using assay kits automatically. Then, sdLDL-C was calculated for all the samples using the arithmetic formula. After a period of six months, the samples were then deanonymized, and the various laboratory lipid profile parameters were correlated with the clinical outcomes in the form of cardiovascular events in the patients, to find out which parameter showed the best correlation.

\section{Results:}

It was observed from the present study that, neither calculated LDL-C $(p=0.468)$ nor direct LDL-C $(p=0.615)$ could be used singly as potential marker for the occurrence of a cardiovascular event in the immediate future. The calculated sdLDL-C also failed to demonstrate any such significance (0.642). Instead, the \% sdLDL-C, both with respect to calculated and direct LDL-C, proved to be of higher predictive value.

\section{Conclusions:}

It can be concluded that LDL-C levels alone or the levels of its individual phenotypes cannot be singly used as surrogate markers suggestive of occurrence of any CVDs in the immediate future.

\section{Background}

Cardiovascular pathology is the leading cause of death and disability in developed nations, and is increasing rapidly in the developing world. It can virtually affect any age group of populations. (1) Due to rapid changes in the life style consequent to economic development, heart disease rates in India have doubled in rural areas and tripled in urban areas. (2) One of the most important advances in medicine has been the identification of the major risk factors associated with cardiovascular diseases (CVDs). (3)

Dyslipidemia is attributed to be one of the key modifiable risk factors for CVDs. Raised triglycerides (TG), very low-density lipoprotein cholesterol (VLDL-C), low-density lipoprotein cholesterol (LDL-C), and reduced 
high-density lipoprotein cholesterol (HDL-C), are considered to be the atherogenic lipid profile indices. (4) Elevated plasma LDL-C levels is an important component of dyslipidemia and lowering LDL-C has been shown to reduce the risk of heart diseases. (4) Hence patients with elevated LDL-C levels are started on pharmacological agents that lower LDL-C, like statins, which can cause severe adverse effects like musculotoxicity, gastrointestinal distress, hepatotoxicity, and other unfavorable drug interactions. (5)

Seven subspecies of LDL-C has been identified based on their metabolic behavior and pathological significance. (6) Austin et al, have identified two distinct phenotypes of LDL-C particles which are - a large and buoyant type called pattern A, IbLDL-C $(>25.5 \mathrm{~nm})$, and a small and dense type called pattern $\mathrm{B}$, sdLDL-C ( $\leq 25.5 \mathrm{~nm})$. (7)

According to National Cholesterol Education Program Adult Treatment Panel III, sdLDL-C is an emerging risk factor for CVDs. (8) sdLDL-C has strongly predicted the rate of coronary heart disease independent of LDL-C in the 13 year follow up Quebec Cardiovascular Study. (9) When LDL-C characteristics were investigated by polyacrylamide gel electrophoresis, the strongest association of risk of CVDs was found to be with sdLDL-C. (10) The Epic Norfolk Study showed that sdLDL-C is associated with reduction in survival rates in the instance of a CVD. (11) Jana Netriova et al, observed that in metabolic syndrome, sdLDL-C is better than the LDL-C, as a valuable marker for the risk of coronary heart disease. (12) It was demonstrated to be an independent risk factor for coronary heart disease even with the use of multivariate logistic and survival models. (13)

Determination of LDL-C can be done in two ways namely, (a) arithmetic calculation based on total cholesterol (TC) using the Friedewald formula, cLDL-C (mg/dL) $=T C-(H D L-C)-(T G / 5)$ and (b) direct estimation (dLDL-C) by using specially designed assays. (14)(15) On the other hand, various means have been adopted for the assessment of sdLDL-C, which includes gradient gel electrophoresis, tube gel electrophoresis, density gradient ultracentrifugation, and nuclear magnetic resonance. (16) These methods are not only exorbitant, arduous, time-demanding, but also technically challenging to be used routinely in clinical practice or for screening a large population. A novel method for the measurement of sdLDL-C has been devised via a simple homogeneous enzymatic assay independent of LDL-C. (17) Though this method is simple to perform and could be effectively used for regular clinical practice, the reagent cost being heavily expensive hinders its general as well as screening application.

Srisawasdi et al, developed cost-effective method for estimation of sdLDL-C concentration based on classic lipid profile indices. This linear regression equation did not significantly vary across different subgroups based on sex, age group, chronic kidney disease stages, and fasting plasma glucose categories and it was suggested to consider using the calculated sdLDL-C in serum samples as a means of assessing CVD risk worldwide in clinical practice. (18), (19)

This study was primarily undertaken to determine and validate any actual association of LDL-C or its phenotype - sdLDL-C, with the occurrence of cardiovascular diseases in the immediate future, in order for them to be utilized as surrogate markers for prediction and prevention of future cardiovascular events. 


\section{Material And Methods}

Study Design, Setting and Population:

This observational analytical cross-sectional study was carried out in the Department of Biochemistry, Kasturba Medical College, Manipal, over a period of six months. The ethical clearance from the Institutional Ethics Committee was obtained prior to the commencement of the study (IEC No: 567/2016) and it was performed in accordance with the principles of the Declaration of Helsinki. In order to estimate sensitivity of sdLDL-C at $80 \%$ with $5 \%$ precision, at $95 \%$ confidence level, 81 samples of each normal and high LDL-C were required for the study. Hence, leftover serum samples from 162 subjects sent for the Fasting Lipid Profile analysis were used.

Data Collection:

The lipid profile data obtained from the laboratory of all the 162 samples include: Total Cholesterol (TC, in $\mathrm{mg} / \mathrm{dL}$ ), Triglyceride (TG, in $\mathrm{mg} / \mathrm{dL}$ ), High Density Lipoprotein-Cholesterol (HDL-C, in $\mathrm{mg} / \mathrm{dL}$ ) and calculated Low Density Lipoprotein-Cholesterol (cLDL-C, in mg/dL, calculated using Friedewald formula). (14)

Based on the lipid profile values, 81 samples, each containing optimal levels of all the lipid profile parameters, and 81 samples containing greater than optimal levels of CLDL-C (that is CLDL-C $\geq$ $130 \mathrm{mg} / \mathrm{dL}$ ) irrespective of the values of other lipid profile parameters, were classified into two groups, and identified as:

- Group 1 (Control) - containing 81 normal samples (that is, subjects who are not prone for the occurrence of any CVDs in the immediate future), and

- Group 2 (Test) - containing 81 test samples (that is, subjects who are at a risk of developing CVD). Here optimal refers to - TC: $150-200 \mathrm{mg} / \mathrm{dL}$, TG: $70-150 \mathrm{mg} / \mathrm{dL}, \mathrm{HDL}-\mathrm{C}: 40-60 \mathrm{mg} / \mathrm{dL}$ and CLDL-C: $<100 \mathrm{mg} / \mathrm{dL}$. It was based on the assumption that cLDL-C $\geq 130 \mathrm{mg} / \mathrm{dL}$, subjects who are at a risk of developing CVD. (20) Anonymized 162 samples (with regards to their identity through the means of a mediator) were then processed for the estimation of direct-LDL-C (dLDL-C, in $\mathrm{mg} / \mathrm{dL}$ ) using assay kits of LCL-Cholesterol plus $2^{\text {nd }}$ generation obtained by Roche/Hitachi cobas c 501 analyzer.

The small, dense Low Density Lipoprotein-Cholesterol (sdLDL-C) values were calculated for all the samples using the formula provided by Srisawasdi, et al:

sdLDL-C (in $\mathrm{mg} / \mathrm{dL}$ ) $=$ [0.580(non-HDL-C) +0.407 (direct $L D L-C)-0.719$ (calculated $L D L-C)-12.05]$. Here non-HDL-C = (TC-HDL-C). (18) The \% sdLDL-C, both with respect to CLDL-C and dLDL-C, was also calculated for all the samples. Routinely, \% sdLDL-C $\leq 30 \%$ of LDL-C is considered to be normal.

After the laboratory analysis of all the samples, followed by a period of six months, the samples were deanonymized (through mediator) and cross-checked with the patients' medical records obtained from Medical Records Department, Kasturba Hospital. All 162 subjects' records were checked for the 
occurrence of any cardiovascular event during the study period (any form of atherosclerotic or ischemic heart diseases). Socio-demographic details, associated comorbidities, personal histories for all participants could not be obtained due to unavailability, hence was not studied.

Plan of analysis/Statistical tool:

The collected data was treated using the Statistical Package for the Social Sciences (SPSS) version 16 (SPSS, South Asia, Bangalore).

\section{Results}

All categorical data are depicted in Table 1 as median and interquartile range of lipid profile parameters in both groups: Control (1) and Test (2). Mann-Whitney U Test was used to draw comparisons. The resistance rate has been expressed as percentage with $95 \%$ confidence level and the results. As a result, a clear statistical difference can be seen between these two groups.

However the review of medical records of all the subjects, after a six-month period, revealed that $\mathbf{4}$ participants from Group 1 (Control) and only 3 participants from Group 2 (Test) had developed a cardiovascular event.

Since there was no significant arithmetical difference in occurrence of CVDs in both the groups $\mathbf{1}$ and $\mathbf{2}$ based on the assessment of lipid profile parameters, all the participants were re-classified into two different groups as follows:

-Group (a)- in whom no cardiovascular event occurred ( $n=155)$, and

- Group (b) - in whom there was an occurrence of cardiovascular event $(n=7)$.

The descriptive percentiles for selective lipid profile parameters and their comparison using MannWhitney U test in Group (a) and Group (b) is depicted in Table 2.

As none of the lipid profile indices showed any significant statistical correlation ( $p>0.05)$, box plots (Figure 1 through 5) were charted, to study the variability of parameters assessed $n$ two groups (a) and (b).

\section{Discussion}

Previously carried out studies, as evident from the literature review, clearly depict the association of high LDL-C levels with atherogenesis. (10), (21) This is in contrast to our present study, where neither the population with elevated CLDL-C nor dLDL-C had such outcomes in the form of CVDs. Based on this observation neither calculated nor laboratory estimated LDL-C could be used singly as potential markers or risk factors for prevention or management of CVDs. 
Previously, study carried out by UCLA had reported that nearly $75 \%$ of patients hospitalized for a heart attack had cholesterol levels that would indicate that they were not at high risk for a CVD based on current national cholesterol guidelines. (22) Study conducted by Patil RS et al on premature CVDs in young Indian population also failed to demonstrate the role of LDL-C as most important primary lipid parameter associated with the severity or occurrence of CVDs. (23) Our study also affirmed the above published results.

Recent studies suggest that elevated levels of sdLDL-C can predict the risk of incident CVDs, even in individuals considered to be at low risk for CVDs based on their LDL-C levels. (24) Studies from University of Zurich showed the pathological significance of sdLDL-C in development of atherosclerosis. (25) In contrast, our study failed to elicit any such association. Study conducted by Goel PK et al on Indian patients with established CVD showed higher sdLDL-C levels compared to individuals without CVDs despite having comparable LDL-C levels. (26) However, in our study, even the calculated sdLDL-C failed to demonstrate any such significance, whereas the percentage of sdLDL-C proved to be of higher predictive value, as evident from the median values in the box plots.

A significant difference in calculated and directly estimated LDL-C was also observed in our study, similar to study conducted by Kannan et al on Indian population. (27) This has to be alerted because generally in all health institutions and laboratories, especially in low-middle income countries, only CLDL-C is obtained based on which a clinician decides treatment plan, using cholesterol lowering agents like statins, which carry their own set of adverse effects. (28), (29) But as such, the results of these observational studies should not necessarily be interpreted as scientific justification to avoid the use of lipid-lowering medications in patients with CVDs, especially those who have other indications for treatment. (30)

Indian healthcare providers rely on guidelines and normative data provided for the western population, to assess and manage the patient population in India, despite there being a staggering difference in the genetic makeup of both. (31) Keeping this in mind, it is also beneficial to have normative laboratory data for our own population, based on large-scale studies carried out on Indians that would aid in appropriate mode of management for different diseases.

\section{Conclusion}

Based on this study, it can be concluded that LDL-C levels alone or the levels of its individual phenotypes can singly not be used as surrogate markers suggestive of the occurrence of any cardiovascular event in the immediate future. Also, it alerts a clinician regarding the same, for prescription of LDL-C lowering medications as the sole measure to counterfeit CVDs. Various genetic, environmental, metabolic and multifarious biochemical factors interplay in cardiovascular contingencies.

\section{Limitations}

- Shorter study period. 
- A larger sample size within the representative Indian population would be required to be implemented as confirmatory evidence.

- Lack of participant's: socio-demographic details, history of exposure to risk factors for CVDs, previous medical/treatment history, associated comorbidities and so on.

\section{Suggestions:}

Development of validated scales for grading the possibility of future CVD occurrence that would be based on a combinations of various individual determinants, with stringent validation of inclusive parameters used for arithmetic discernment. This could guide a clinician with regards to treatment and outcomes.

\section{Abbreviations}

CVD(s) : Cardiovascular Disease(s)

LDL-C : Low-density lipoprotein cholesterol

CLDL-C : Calculated LDL-C dLDL-C : Directly estimated LDL-C

sdLDL-C : Small and dense LDL-C

TG : Triglycerides

VLDL-C : Very low-density lipoprotein cholesterol

HDL-C : High-density lipoprotein cholesterol

IbLDL-C : Large and buoyant LDL-C

\section{Declarations}

Ethics approval and consent to participate: The ethical clearance was approved before the commencement of this study from the Institutional Ethics Committee (IEC) at Kasturba Medical College, Manipal. (IECNo: 567/2016) and it was performed in accordance with the principles of the Declaration of

Consent for publication: Manuscript has been read and approved by all the authors and the requirements for authorship have been met. Authors believe that the manuscript represents honest work. All authors give their consent for the publication.

Availability of data and materials: The data will be available and provided to readers/reviewers by contacting the corresponding author anytime within 2 years of publication.

Competing interests: The authors declare that they have no actual or potential conflicts of interest to disclose. 
Funding: This project received funding from Kasturba Medical College - Short Term Studentship (KMCSTS) for the year 2016-17.

\section{Authors' contributions:}

Conceptualization: Sufyan Ibrahim, Anurupa Udupi, Revathi P Shenoy

Data curation: Cleeta Rebeiro, Sufyan Ibrahim, Anurupa Uduapi

Methodology: Sufyan Ibrahim, Revathi P Shenoy, Asha Kamath, Cleeta Rebeiro

Formal analysis: Asha Kamath, Cleeta Rebeiro, Varashree B S, Revathi P Shenoy

Supervision: Revathi P Shenoy, Varashree B S, Asha Kamath

Validation: Revathi P Shenoy, Sufyan Ibrahim, Anurupa Udupi

Writing - original draft: Sufyan Ibrahim, Anurupa Udupi, Revathi P Shenoy

Writing - review \&amp; editing: Sufyan Ibrahim, Anurupa Udupi, Cleeta Rebeiro, Varashree B S, Asha Kamath, Revathi P Shenoy

Acknowledgements: Authors would like to acknowledge Kasturba Medical College and Kasturba Hospital, Manipal for permitting to carry out the study.

\section{References}

1. Berneis KK, Krauss RM. Metabolic origins and clinical significance of LDL heterogeneity [Internet]. Vol. 43, Journal of Lipid Research. J Lipid Res; 2002 [cited 2020 Oct 9]. p. 1363-79. Available from: https://pubmed.ncbi.nlm.nih.gov/12235168/

2. Krishnan MN. Coronary heart disease and risk factors in India - On the brink of an epidemic? [Internet]. Vol. 64, Indian Heart Journal. Elsevier B.V.; 2012 [cited 2020 Oct 17]. p. 364-7. Available from: https://www.ncbi.nlm.nih.gov/pmc/articles/PMC3860846/

3. Sialvera TE, Papadopoulou A, Efstathiou SP, Trautwein EA, Ras RT, Kollia N, et al. Structured advice provided by a dietitian increases adherence of consumers to diet and lifestyle changes and lowers blood low-density lipoprotein (LDL)-cholesterol: the Increasing Adherence of Consumers to Diet \& Lifestyle Changes to Lower (LDL) Cholesterol (ACT) randomised controlled trial. J Hum Nutr Diet [Internet]. 2018 Apr 1 [cited 2020 Oct 9];31(2):197-208. Available from:

https://pubmed.ncbi.nlm.nih.gov/28891084/

4. Hernáez Á, Soria-Florido MT, Schröder H, Ros E, Pintó X, Estruch R, et al. Role of HDL function and LDL atherogenicity on cardiovascular risk: A comprehensive examination. PLoS One [Internet]. 2018 Nov 1 [cited 2020 Oct 9];14(6). Available from: https://pubmed.ncbi.nlm.nih.gov/31246976/ 
5. McKenney JM. Optimizing LDL-C lowering with statins. [Internet]. Vol. 11, American journal of therapeutics. Am J Ther; 2004 [cited 2020 Oct 9]. p. 54-9. Available from: https://pubmed.ncbi.nlm.nih.gov/14704596/

6. Krauss RM, Burke DJ. Identification of multiple subclasses of plasma low density lipoproteins in normal humans. J Lipid Res [Internet]. 1982 [cited 2020 Oct 9];23(1):97-104. Available from: https://pubmed.ncbi.nlm.nih.gov/7057116/

7. Austin MA, King MC, Vranizan KM, Krauss RM. Atherogenic lipoprotein phenotype. A proposed genetic marker for coronary heart disease risk. Circulation [Internet]. 1990 [cited 2020 Oct 9];82(2):495-506. Available from: https://pubmed.ncbi.nlm.nih.gov/2372896/

8. Cleeman Jl. Executive summary of the third report of the National Cholesterol Education Program (NCEP) expert panel on detection, evaluation, and treatment of high blood cholesterol in adults (adult treatment panel III). J Am Med Assoc [Internet]. 2001 May 16 [cited 2020 Oct 9];285(19):2486-97. Available from: https://pubmed.ncbi.nlm.nih.gov/11368702/

9. St-Pierre AC, Cantin B, Dagenais GR, Mauriège P, Bernard PM, Després JP, et al. Low-density lipoprotein subfractions and the long-term risk of ischemic heart disease in men: 13-year follow-up data from the Québec Cardiovascular Study. Arterioscler Thromb Vasc Biol. 2005 Mar;25(3):553-9.

10. Carmena R, Duriez P, Fruchart JC. Atherogenic lipoprotein particles in atherosclerosis. Vol. 109, Circulation. 2004.

11. Arsenault BJ, Lemieux I, Després JP, Wareham NJ, Luben R, Kastelein JJP, et al. Cholesterol levels in small LDL particles predict the risk of coronary heart disease in the EPIC-Norfolk prospective population study. Eur Heart J [Internet]. 2007 Nov 1 [cited 2020 Oct 17];28(22):2770-7. Available from: https://academic.oup.com/eurheartj/article/28/22/2770/427926

12. Netriová J, Meluš V, Krajčovičová Z, Kalúsová N. ASSESMENT OF SMALL DENSITY LDL IN FAMILIAR CARDIOVASCULAR RISK. Vol. 9, Jana Netriová / University Review. 2015.

13. Nanda R, Panda S, Mangaraj M. Issue: 6. Int J Heal Sci Res [Internet]. 2015 [cited 2020 Oct 9];5:598. Available from: www.ijhsr.org

14. W T Friedewald, R I Levy DSF. Estimation of the concentration of low-density lipoprotein cholesterol in plasma, without use of the preparative ultracentrifuge. Clin Chem. 1972;18(6):499-502.

15. Lindsey CC, Graham MR, Johnston TP, Kiroff CG, Freshley A. A Clinical Comparison of Calculated versus Direct Measurement of Low-Density Lipoprotein Cholesterol Level. Pharmacotherapy [Internet]. 2004 Feb [cited 2020 Oct 17];24(2 I):167-72. Available from: https://pubmed.ncbi.nlm.nih.gov/14998216/

16. Ivanova EA, Myasoedova VA, Melnichenko AA, Grechko A V., Orekhov AN. Small Dense Low-Density Lipoprotein as Biomarker for Atherosclerotic Diseases. Oxid Med Cell Longev [Internet]. 2017 [cited 2020 Oct 17];2017. Available from: /pmc/articles/PMC5441126/?report=abstract

17. Tsai MY, Steffen BT, Guan W, McClelland RL, Warnick R, McConnell J, et al. New automated assay of small dense low-density lipoprotein cholesterol identifies risk of coronary heart disease: The multi- 
ethnic study of atherosclerosis. Arterioscler Thromb Vasc Biol [Internet]. 2014 Jan [cited 2020 Oct 17];34(1):196-201. Available from: /pmc/articles/PMC4211254/?report=abstract

18. Srisawasdi P, Chaloeysup S, Teerajetgul Y, Pocathikorn A, Sukasem C, Vanavanan S, et al. Estimation of plasma small dense LDL cholesterol from classic lipid measures. Am J Clin Pathol [Internet]. 2011 Jul [cited 2020 Oct 17];136(1):20-9. Available from: https://pubmed.ncbi.nlm.nih.gov/21685028/

19. Palazhy S, Kamath P. Estimation of Small, Dense LDL Particles Using Equations Derived From Routine Lipid Parameters as Surrogate Markers. Biochem Anal Biochem [Internet]. 2014 [cited 2020 Oct 17];3(1):1-5. Available from: https://www.longdom.org/abstract/estimation-of-small-dense-ldlparticles-using-equations-derived-fromroutine-lipid-parameters-as-surrogate-markers-33613.html

20. Gulati A, Sreenivas C, Talwalkar P, Baxi H. Journey in guidelines for lipid management: From adult treatment panel (ATP)-I to ATP-III and what to expect in ATP-IV. Indian J Endocrinol Metab [Internet]. 2013 [cited 2020 Oct 17];17(4):628. Available from: /pmc/articles/PMC3743362/?report=abstract

21. Gupta S, Bhise M, Gaurav K, Gudapati R. Emerging risk factors for cardiovascular diseases: Indian context. Indian J Endocrinol Metab [Internet]. 2013 [cited 2020 Oct 17];17(5):806. Available from: /pmc/articles/PMC3784863/?report=abstract

22. Sachdeva A, Cannon CP, Deedwania PC, LaBresh KA, Smith SC, Dai D, et al. Lipid levels in patients hospitalized with coronary artery disease: An analysis of 136,905 hospitalizations in Get With The Guidelines. Am Heart J [Internet]. 2009 [cited 2020 Oct 17];157(1). Available from:

https://pubmed.ncbi.nlm.nih.gov/19081406/

23. Patil R, Raghu T, Manjunath C, Ghosh S, Shetty L. Distribution of conventional lipids in Indians with premature coronary artery disease: A substudy of the premature coronary artery disease registry. $\mathrm{J}$ Clin Prev Cardiol. 2019;

24. Hoogeveen RC, Gaubatz JW, Sun W, Dodge RC, Crosby JR, Jiang J, et al. Small dense low-density lipoprotein-cholesterol concentrations predict risk for coronary heart disease: The Atherosclerosis Risk in Communities (ARIC) study. Arterioscler Thromb Vasc Biol [Internet]. 2014 [cited 2020 Oct 17];34(5):1069-77. Available from: /pmc/articles/PMC3999643/?report=abstract

25. Gerber PA, Nikolic D, Rizzo M. Small, dense LDL: An update [Internet]. Vol. 32, Current Opinion in Cardiology. Lippincott Williams and Wilkins; 2017 [cited 2020 Oct 17]. p. 454-9. Available from: https://pubmed.ncbi.nlm.nih.gov/28426445/

26. Goel PK, Ashfaq F, Khanna R, Ramesh V, Pandey CM. The Association Between Small Dense Low Density Lipoprotein and Coronary Artery Disease in North Indian Patients. Indian J Clin Biochem [Internet]. 2017 Jun 1 [cited 2020 Oct 17];32(2):186-92. Available from:

/pmc/articles/PMC5382077/?report=abstract

27. Kannan S, Mahadevan S, Ramji B, Jayapaul M, Kumaravel V. LDL-cholesterol: Friedewald calculated versus direct measurement-study from a large Indian laboratory database. Indian J Endocrinol Metab [Internet]. 2014 Jul 1 [cited 2020 Oct 17];18(4):502-4. Available from: /pmc/articles/PMC4138905/? report=abstract 
28. Pinal-Fernandez I, Casal-Dominguez M, Mammen AL. Statins: pros and cons [Internet]. Vol. 150, Medicina Clinica. Ediciones Doyma, S.L.; 2018 [cited 2020 Oct 17]. p. 398-402. Available from: /pmc/articles/PMC6019636/?report=abstract

29. Menon AS, Kotwal N, Singh Y, Girish R. Statins: Cholesterol guidelines and Indian perspective [Internet]. Vol. 19, Indian Journal of Endocrinology and Metabolism. Medknow Publications; 2015 [cited 2020 Oct 17]. p. 546-53. Available from: / pmc/articles/PMC4566333/?report=abstract

30. Fonarow GC. Cholesterol and Mortality in Heart Failure: The Bad Gone Good?*. J Am Coll Cardiol. 2003;42:1941-3.

31. Malati T. Whether western normative laboratory values used for clinical diagnosis are applicable to Indian population? An overview on reference interval [Internet]. Vol. 24, Indian Journal of Clinical Biochemistry. Springer; 2009 [cited 2020 Oct 17]. p. 111-22. Available from: /pmc/articles/PMC3453230/?report=abstract

\section{Tables}

Table 1: Descriptive percentiles (median and interquartile range) for selected lipid profile indices in groups (1) and (2).

\begin{tabular}{|llll|}
\hline Reference Parameters & $\begin{array}{l}\text { Group 1 (Control) } \\
{[n=81]} \\
\text { Median }(\mathrm{Q} 1, \mathrm{Q} 3)\end{array}$ & $\begin{array}{l}\text { Group 2 (Test) } \\
{[\mathrm{n}=81]}\end{array}$ & M-Value \\
\hline TC & $146(124.5,161)$ & $237.00(214.50,268.50)$ & $0.000^{*}$ \\
\hline TG & $108(82,148.5)$ & $127.00(99.50,180.50)$ & $0.030^{*}$ \\
\hline HDL-C & $44(31.50,51)$ & $46.00(39.50,54.50)$ & $0.005^{*}$ \\
\hline CLDL-C & $74(59.5,89.5)$ & $154.00(142.50,184.50)$ & $0.000^{*}$ \\
\hline dLDL-C & $74(57.5,91)$ & $157(147,187.5)$ & $0.000^{*}$ \\
\hline sdLDL-C & $21.63(16.23,29.30)$ & $46.867(39.995,58.90)$ & $0.000^{*}$ \\
\hline
\end{tabular}

Table 2: Descriptive percentiles (median and interquartile range) for selected lipid profile parameters in groups (a) and (b). 


\begin{tabular}{|llll|}
\hline Reference Parameters & $\begin{array}{l}\text { Group (a) (Control) } \\
\text { [n= 155] } \\
\text { Median (Q1,Q3) }\end{array}$ & $\begin{array}{l}\text { Group (b) (Test) } \\
{[n=7]}\end{array}$ & p-Value \\
\hline cLDL-C & $131(86,152)$ & $90(81,142)$ & 0.468 \\
\hline dLDL-C & $119(92,155)$ & $100(91,150)$ & 0.615 \\
\hline sdLDL-C & $34.97(24.84,45.33)$ & $28.29(26.11,37.52)$ & 0.642 \\
\hline (sdLDL-C/cLDL-C)*100 & $29.12(26.4,32.95$ & $30.63(28.43,32.9)$ & 0.720 \\
\hline (sdLDL-C/dLDL-C)*100 & $27.74(25.58,31.18)$ & $29.73(27.2,30.89)$ & 0.683 \\
\hline
\end{tabular}

Figures

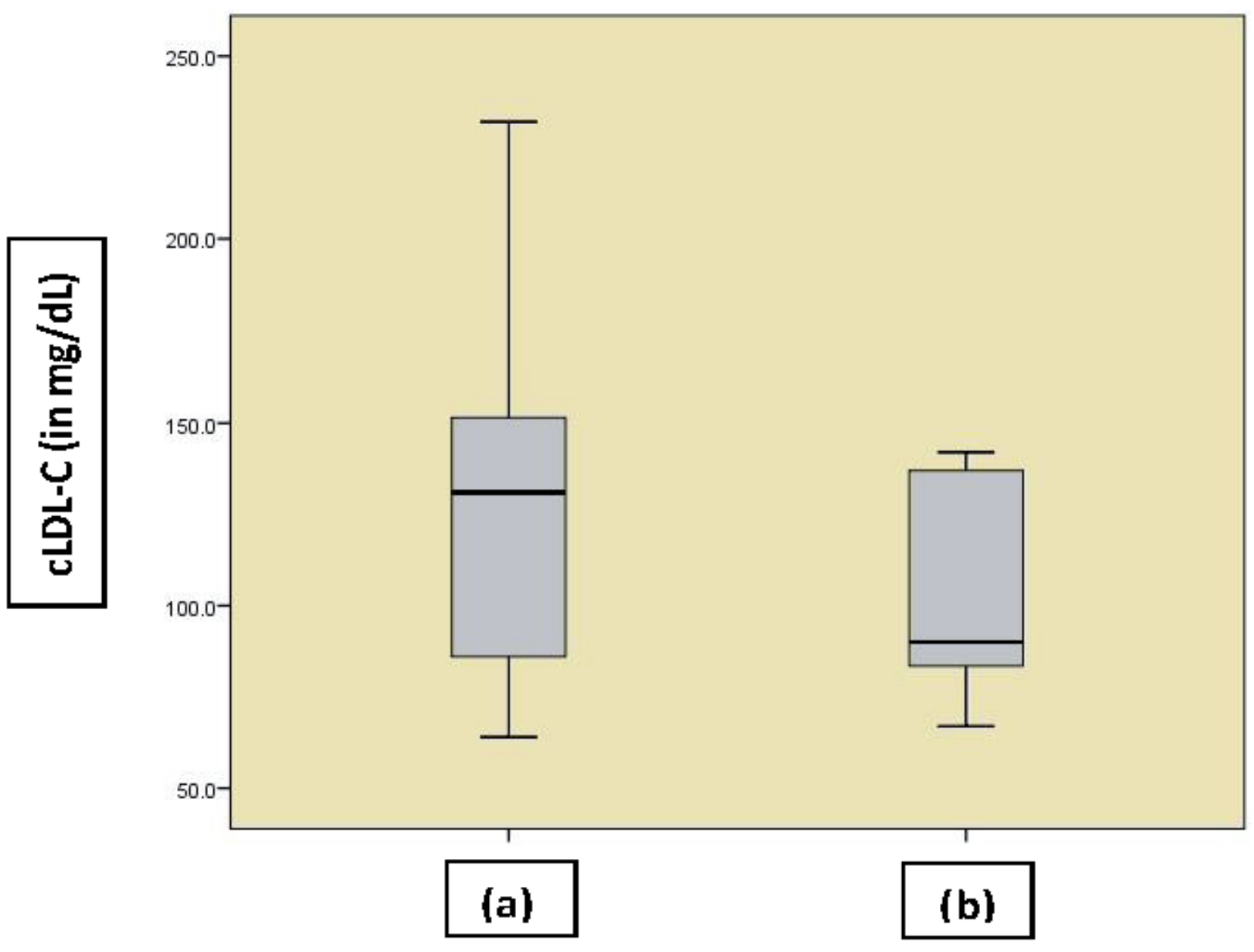

Figure 1 
Box graph showing the comparison and median difference in calculated LDL-C in group (a) [ $n=155]$, and group (b) [n=7]. It appears that the group (a) had significantly higher average cLDL-C values compared to group (b).

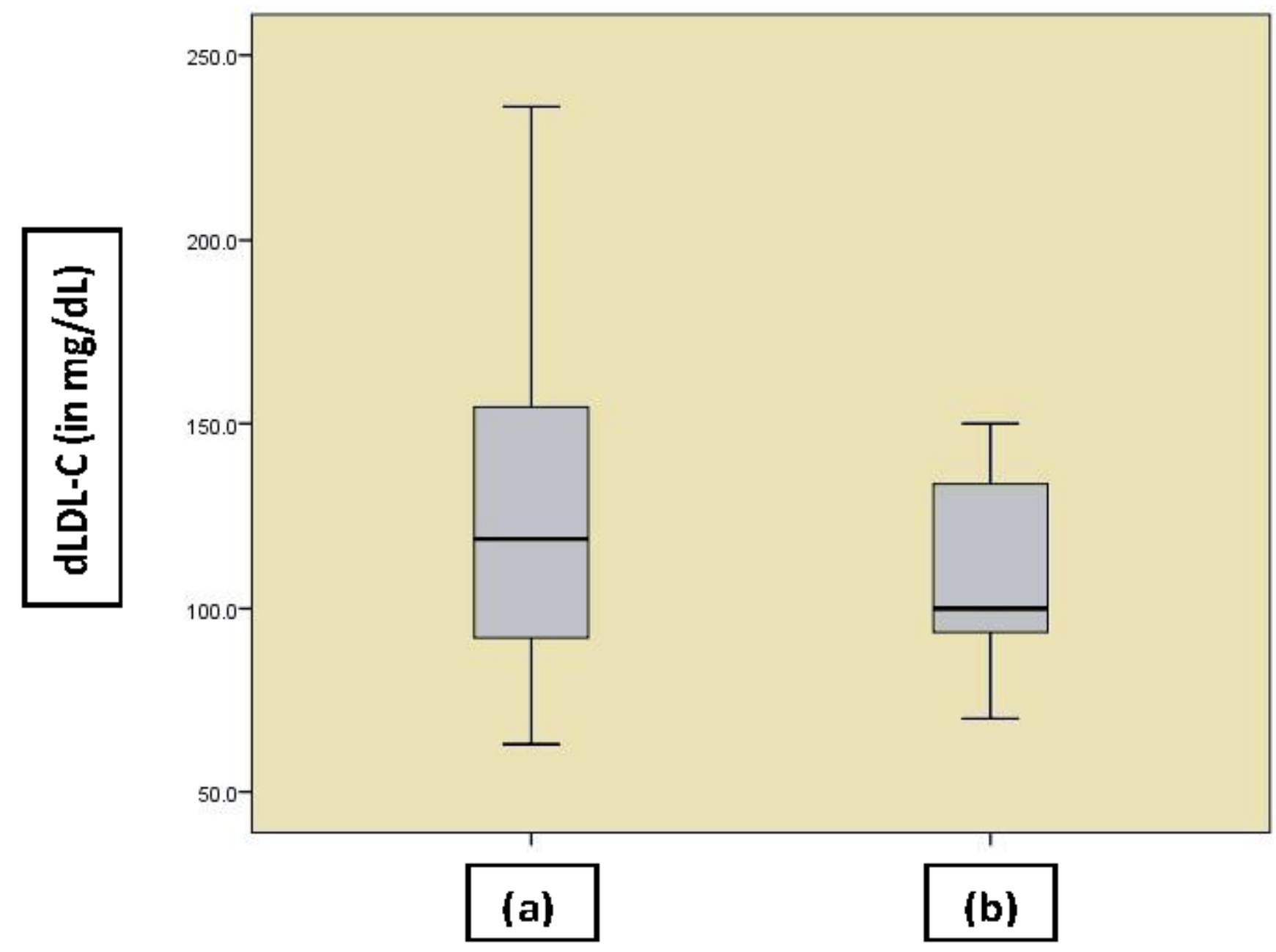

Figure 2

Box graph showing the comparison and median difference in direct LDL-C in group (a) [n=155], and group (b) [n=7]. It appears that the group (a) had significantly higher average dLDL-C values compared to group (b). 


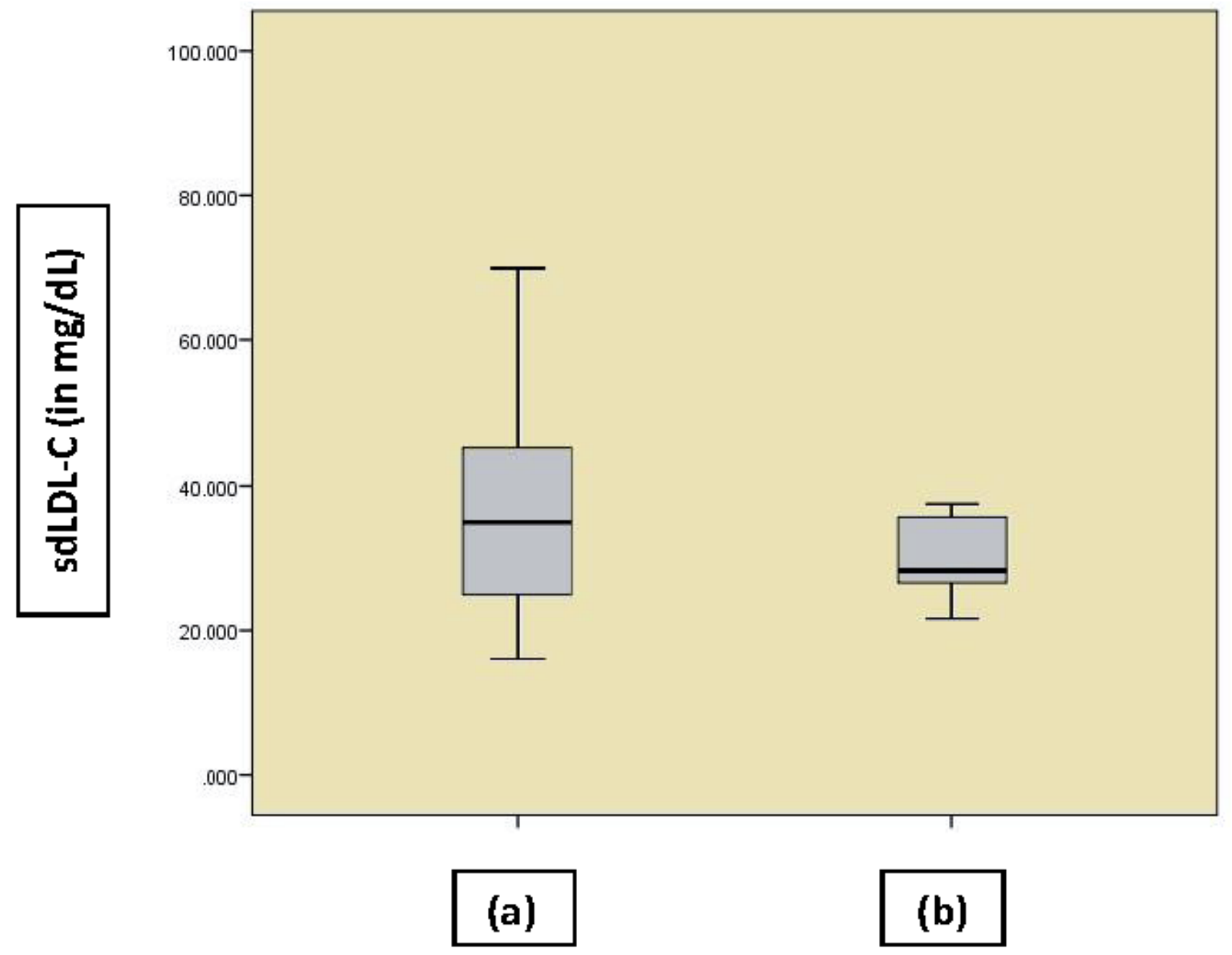

Figure 3

Box graph showing the comparison and median difference in calculated sdLDL-C in group (a) [ $n=155]$, and group (b) [n=7]. It appears that the group (a) had almost similar average sdLDL-C values as that of group (b). 


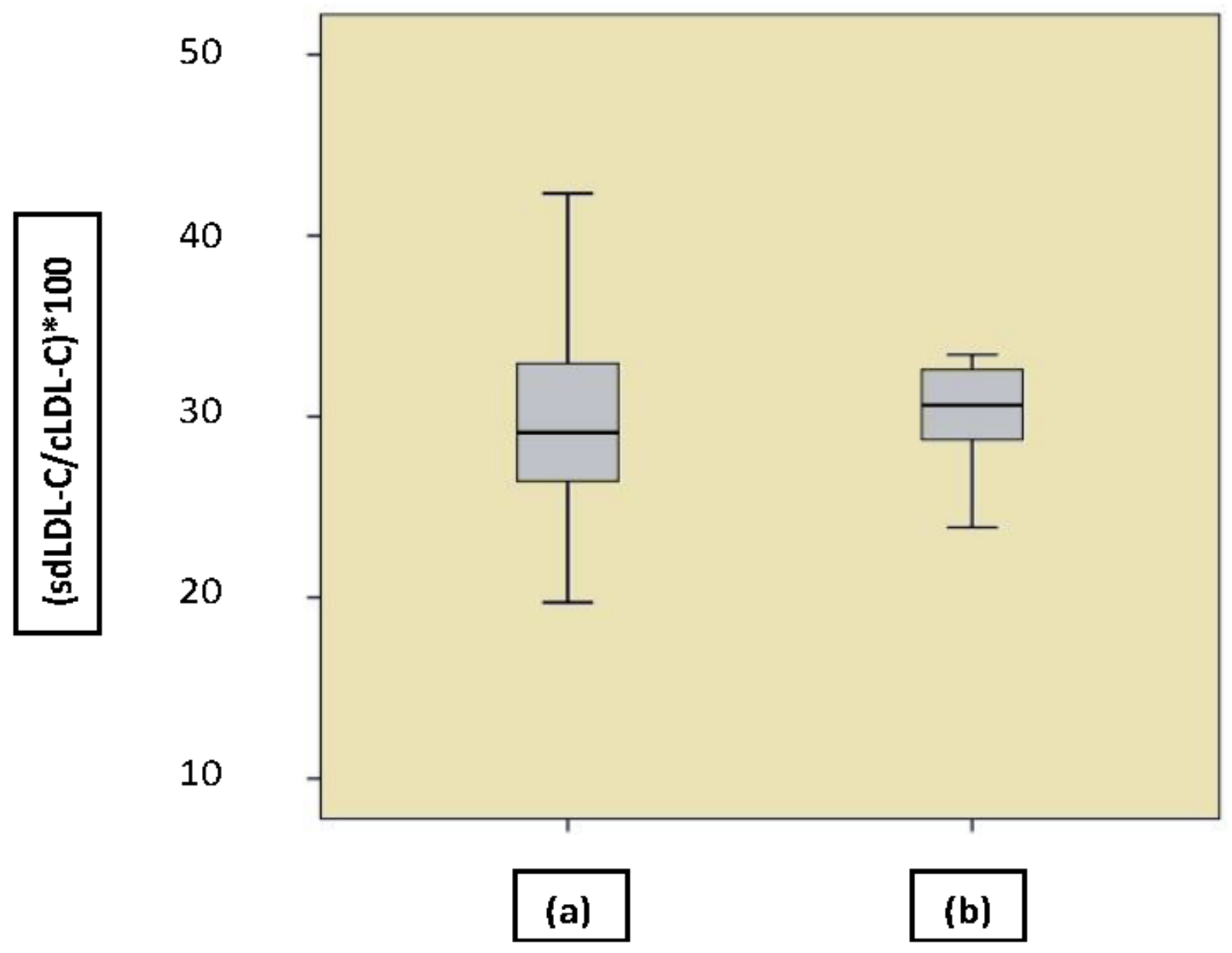

Figure 4

Box graph showing the comparison and median difference in \% sdLDL-C w.r.t. CLDL-C [ (sdLDL-C / CLDL-C)*100] in group (a) [n=155], and group (b) [n=7]. It appears that the group (b) had slightly higher average \% sdLDL-C w.r.t. CLDL-C values compared to group (a), as opposed to the previous graphs. 


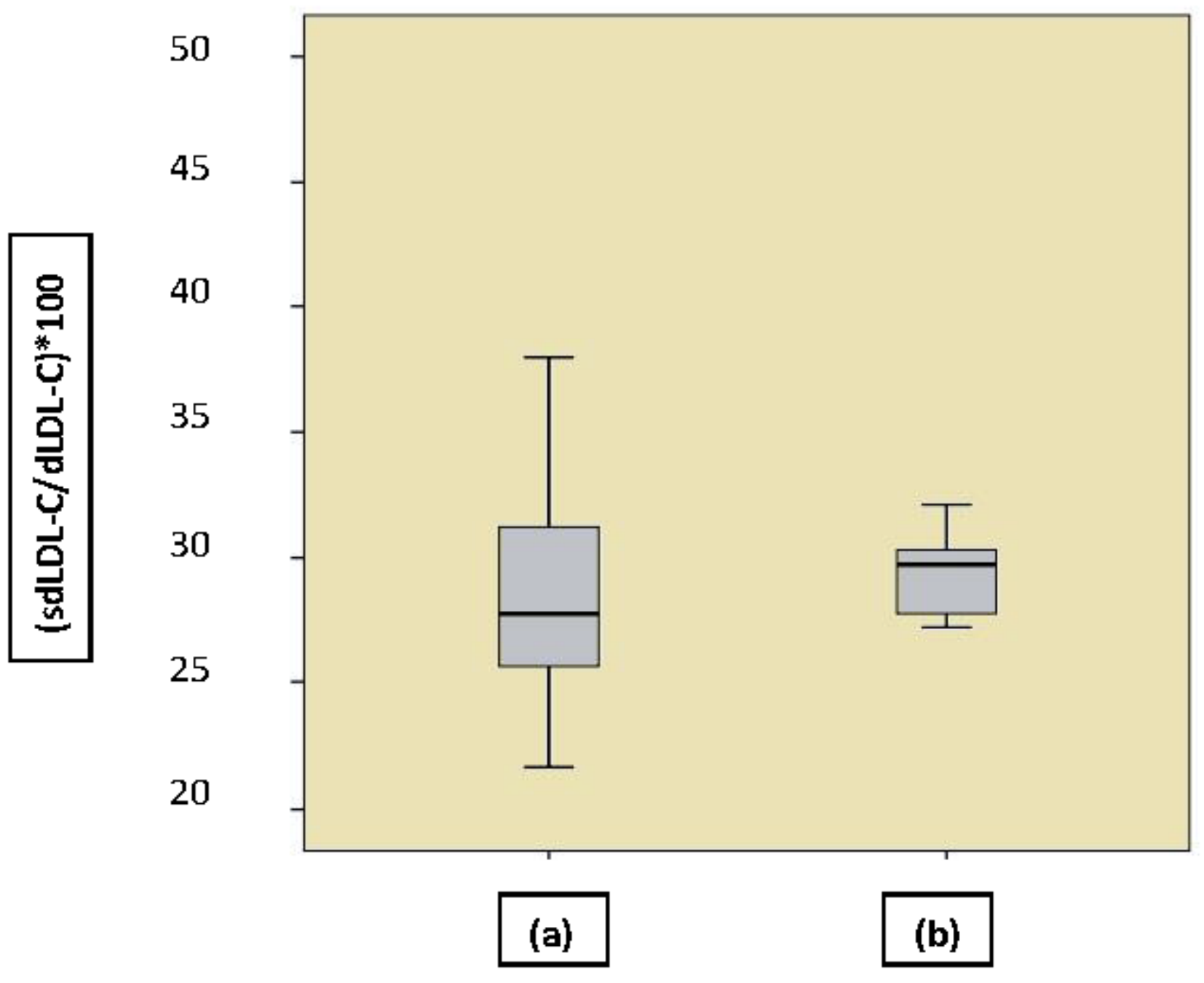

Figure 5

Box graph showing the comparison and median difference in \% sdLDL-C w.r.t. dLDL- in group (a) [n=155], and group (b) [n=7]. It appears that the group (b) had slightly higher average \% sdLDL-C w.r.t. dLDL-C values compared to (a), which could be predictive of the risk of developing CVD. 